\title{
Performance of a Curtainwall in the Magnitude 6.3 Christchurch Earthquake of February 22, 2011
}

\author{
Peter Lalas \\ Janus Facades Pty Ltd, Sydney 2019, Australia
}

\begin{abstract}
On February 22, 2011, Christchurch in New Zealand experienced a magnitude 6.3 earthquake which devastated many of the buildings in the city, especially those made of masonry construction. Janus Facades was asked to inspect the façade of a fourteen storey building which had a curtainwall-clad tower and granite and tile cladding on the three storey podium. The unitised curtainwall was not well designed. It did not have adequately sized joints in accordance with industry standards to absorb seismic effects and it was never really weathertight. Most of the damage to the curtainwall was caused by the damaged structure. Damage to the structure and internal fittings was also observed.
\end{abstract}

Key words: Curtainwall. earthquake, seismic capability, moveable joints.

\section{Introduction}

Several earthquakes of significance occurred in Christchurch, in the south island of New Zealand in 2010 and 2011. Janus Facades was asked to inspect the curtainwall on the 14-floor PWC (Price Waterhouse Coopers) Centre building at 119 Armagh St, Christchurch (Fig. 1) to assess the façade damage. The architect was from Alum Willkie Architects Ltd. According to the few drawings with which Janus Facades had been issued, the building was built in 1989/1990 by Wilkins \& Davies Ltd. The building structure is reinforced concrete (columns, beams and floors). The contemporary loading standard at that time was NZS 4203:1992 Part 4 Earthquake Provisions [1]. The standard has since been updated and combined with the Australian Standard AS1170 [2] in 2002 and upgraded again after the Christchurch February 22, 2011 earthquake.

The tower is substantially clad in an aluminium and glass curtainwall. There are also some parts of the façade clad with granite and some with ceramic tiles, both backed by CFC (compressed fibre cement) sheets,

Corresponding author: Peter Lalas, B.Eng. (Aero), C.P.Eng, research fields: facades and cladding weather resistance.E-mail: peter@janusfacades.com. which are fixed to a timber frame.

The curtainwall type is unitized, being made of interlocked curtainwall panels. This means that panels (or units) were assembled with glazed visions in the fabricator's factory and the curtainwall panels were installed on site, with movable joints between the panels. The colored glass spandrels were probably glazed on site, after the curtainwall brackets had been bolted to the structure. The typical curtainwall panel size is sill to sill $(3.9 \mathrm{~m})$ and mullion to mullion (1.2 m).

The façade fabricator ceased to trade many years ago and its drawings for the facade are not available. Accordingly, Janus relied on visual inspections and experience in analyzing the curtainwall façade.

\section{Earthquake Design of Curtainwalls}

There are very few standards for curtainwalls. Those that are in effect such a Singapore Standard CP96:2002 [3] "Code of Practice for Curtain walls" provide requirements for performance, such as weather-tightness and wind resistance but give no guidelines for design. Some country building codes such as the New Zealand Building Code [4] and Australia's National Construction Code [5] give performance requirements 


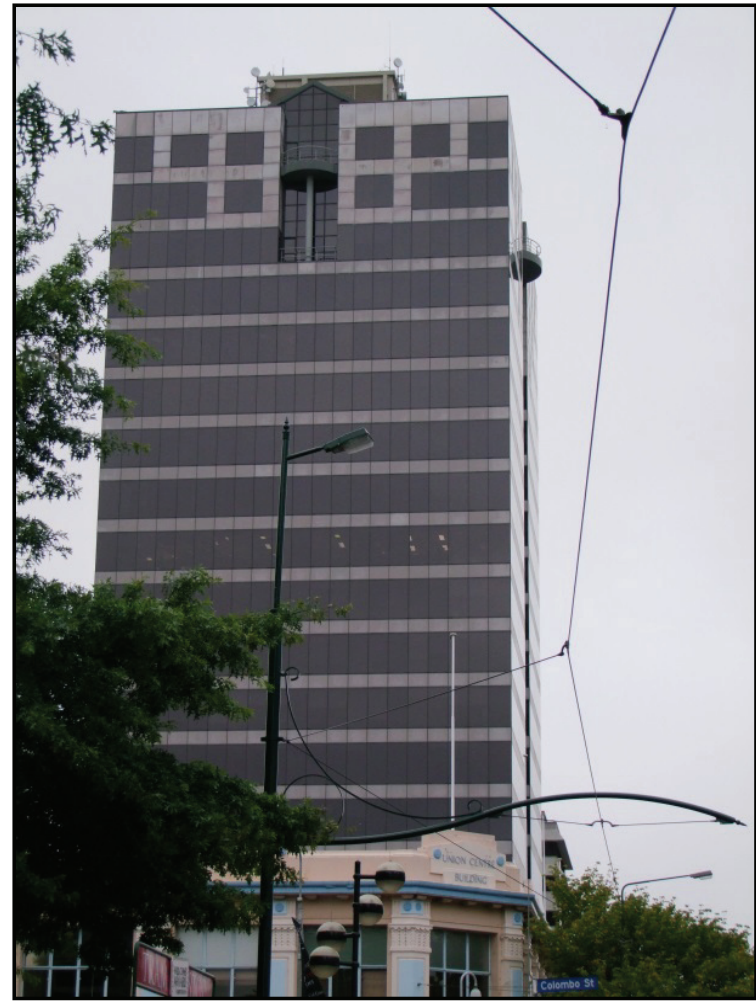

(a)

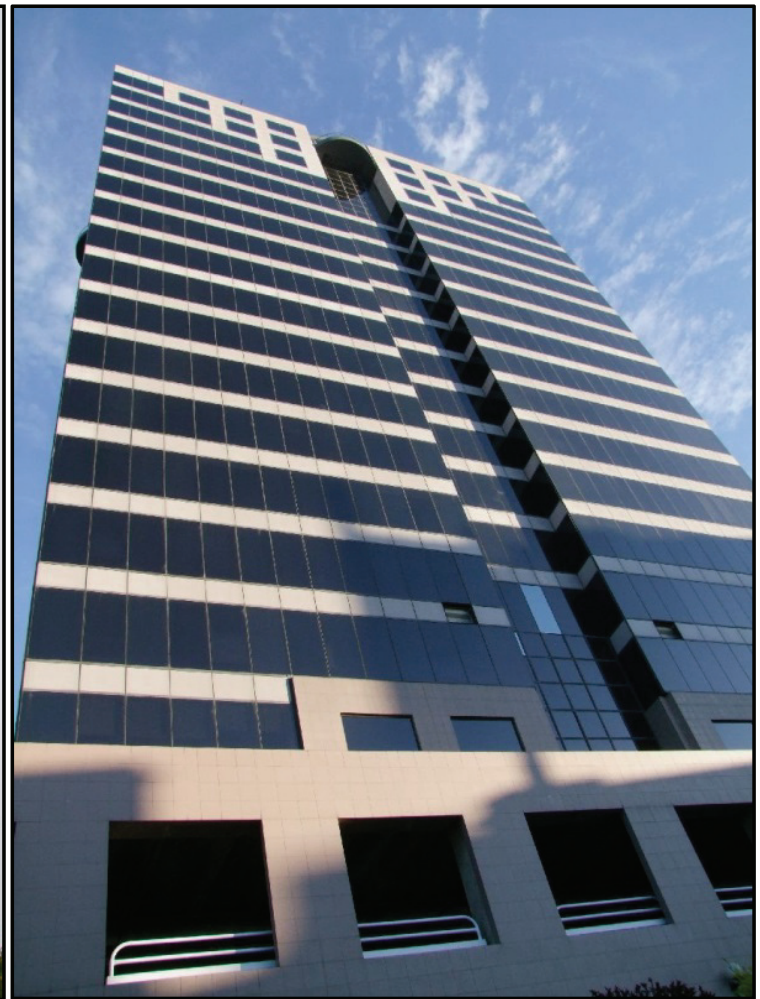

(b)

Fig. 1 PWC tower: (a) the west face of the on February 5, 2011; (b) the south face on May 9, 2011 (no damage is observed on this scale).

for weather-tightness, structural adequacy and fire resistance, but also give no design assistance.

The design knowledge to design a reasonable quality curtainwall which performs adequately in all predictable conditions including weather and building movements (thermal and seismic) is retained by the better curtainwall companies and façade consultants around the world. They design using "façade industry accepted practice" retaining their specific knowledge and guarding it as their own intellectual property.

Some information is provided by AAMA (American Architectural Manufacturers Association) in their CW-DG-1-96Editorial Revision: 5/2005Curtain Wall Design Guide Manual [6]. In Section b "Provision for Movement", Page 13, the following text emphasises the requirements for curtainwall joints as follows:

"It becomes axiomatic, therefore, that the secret of a functionally successful curtain wall lies in the design of its joints. Consequently, the detailing of the joints is the most critical, and often the most difficult aspect of any curtain wall design. It doesn't necessarily follow, however, that by using larger wall units and thus fewer joints the problem will be simplified. This is seldom the case. The larger the units, or the longer the members, the greater will be the amount of movement to be accommodated at each joint, and this tends to complicate, rather than simplify the joint design."

This is an important and true observation, but it gives no quantitative design assistance and the document makes no specific reference to seismic movements.

Another reference is Canada's 'Glass and Metal CurtainWalls Best Practice Guide Building Technology" 2004 CMHC SCHL [7]. This has a short Section "4.2.3 Seismic Loading" which gives the following advice:

\section{“Actual Lateral Drift}

Designing a curtain wall to allow for the maximum allowable lateral drift is often overly conservative and onerous. The structural engineer should be asked to 
provide the actual expected drift not the maximum code allowable for purposes of curtain wall design."

This is also a good advice and should always be followed. However, no guidance is given on how to determine the required sizes of joints in a curtainwall to accommodate the actual expected inter-storey drift as advised by the building structural engineer.

It is therefore left up to the designer to use its best information and experience to determine the size of joints required in a bespoke curtainwall to accommodate the expected movements on the particular building for which the curtainwall is designed.

\section{Christchurch Earthquakes in 2010 2011}

At 4:35 a.m., September 4, 2010, the Canterbury region was rocked by a magnitude 7.1 earthquake. The earthquake was based near Darfield, about $40 \mathrm{~km}$ west of Christchurch. Many buildings were damaged, but only one person died (of a heart attack) and few people were injured.

Following this earthquake, Janus was engaged to assess the damage to the PWC Centre building and made a photographic record of its condition.

On Tuesday February 22, 2011 at 12:51 p.m. Christchurch was badly damaged by a magnitude 6.3 earthquake, which killed 185 people and injured several thousand. The earthquake epicenter was near Lyttelton, just $10 \mathrm{~km}$ south-east of Christchurch's central business district. The earthquake occurred more than five months after the September 4, 2010 earthquake, but is considered to be an aftershock of the earlier quake [8].

The February 22, 2011 earthquake has generated a significant series of its own aftershocks, many of which are considered big for a 6.3 quake. There were 361+ aftershocks (magnitude 3+) experienced in the first week, the largest measuring magnitude 5.9, which occurred just under 2 hours after the main shock.

Janus returned to Christchurch for a re-inspection and assessment of the PWC Centre façade on May 9 and 10, 2011, once entry was allowed into the "red zone"; i.e., the most affected area of the CBD (central business district). Peter Lalas experienced the aftershock which hit the Christchurch region on May 10, 2011 from the Greendale fault measuring 5.3 magnitude. It cut power for a few minutes and caused further damage to buildings in the city centre.

\section{Observations}

Janus inspected all parts of the PWC Centre façade and has identified the following façade systems:

- the tower curtainwall;

- the tower granite cladding;

- the podium granite cladding;

- the tower tile cladding;

- the podium tile cladding.

The curtainwall was never weathertight. Water has been running down the mullion side face (Fig. 2; yellow arrow). The red arrow in Fig. 2 indicates the bottom face of the head transom. The white arrow in Fig. 2 indicates the "fire stop" panel which is not sealed and so is ineffective. The light coming through the joints (Fig. 2; green arrow) is light from the spandrel above. There is no back-pan and water which penetrates the spandrel can fall on the "fire stop panel" and penetrate into the building interior. There are also water streaks on the jamb adaptor (Fig. 2; blue arrow).

The glass in the curtainwall has remained substantially intact through the earthquakes. The glass is silicone glazed to the mullions and transoms. This means that structural silicone sealant bonds the glass to the aluminium frames and is the only medium which retains the glass against negative wind pressures. A continuous silicone seal also separates the glass perimeter from the aluminium frames, forming a buffer between the glass and aluminium. The silicone glazing sealant performed well, showing no obvious damage. It may have also cushioned the glass from impacting the curtainwall panel frames thus minimizing glass breakage. 


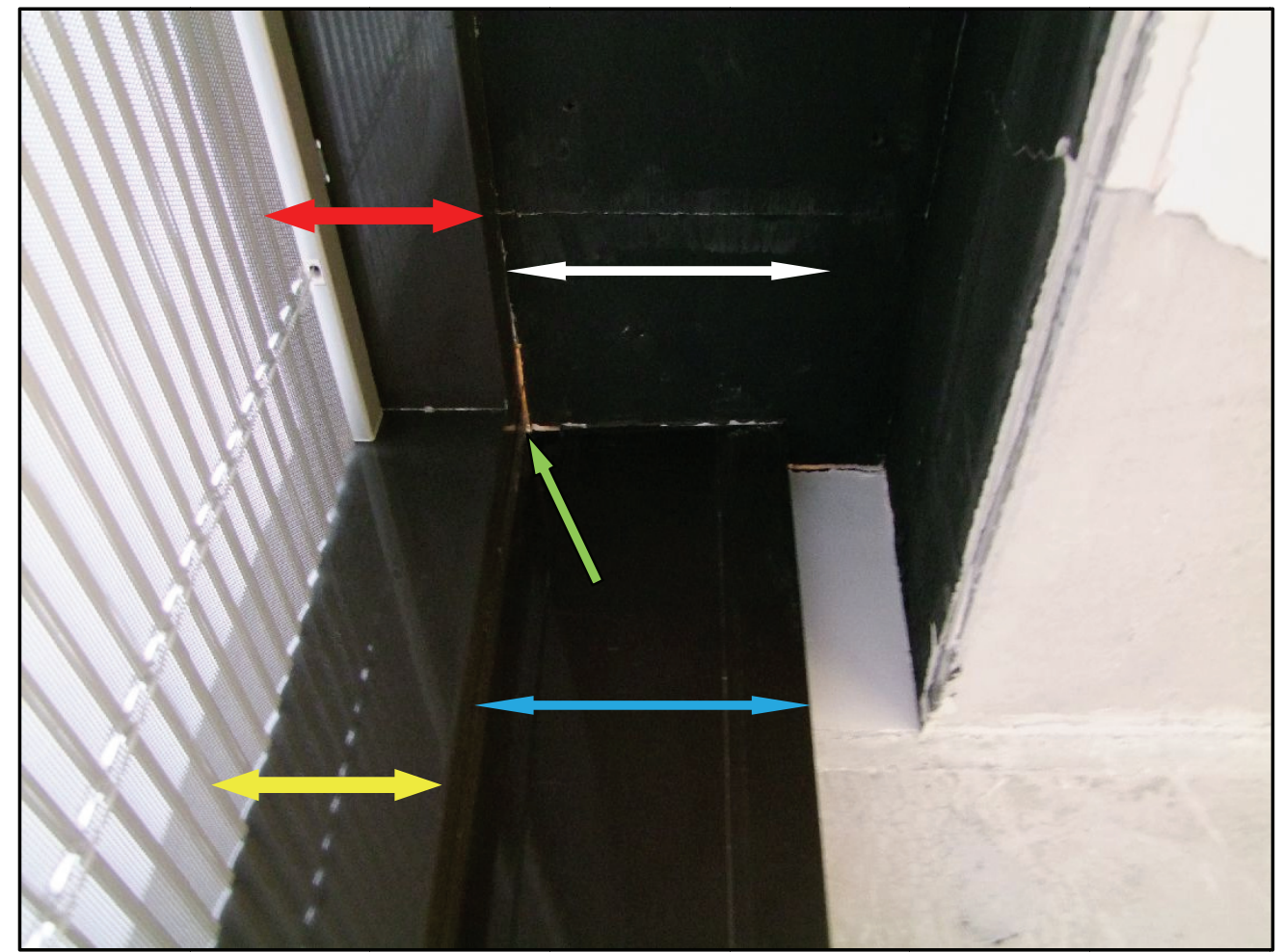

Fig. 2 Mullion/head transom joint (February 5, 2011).

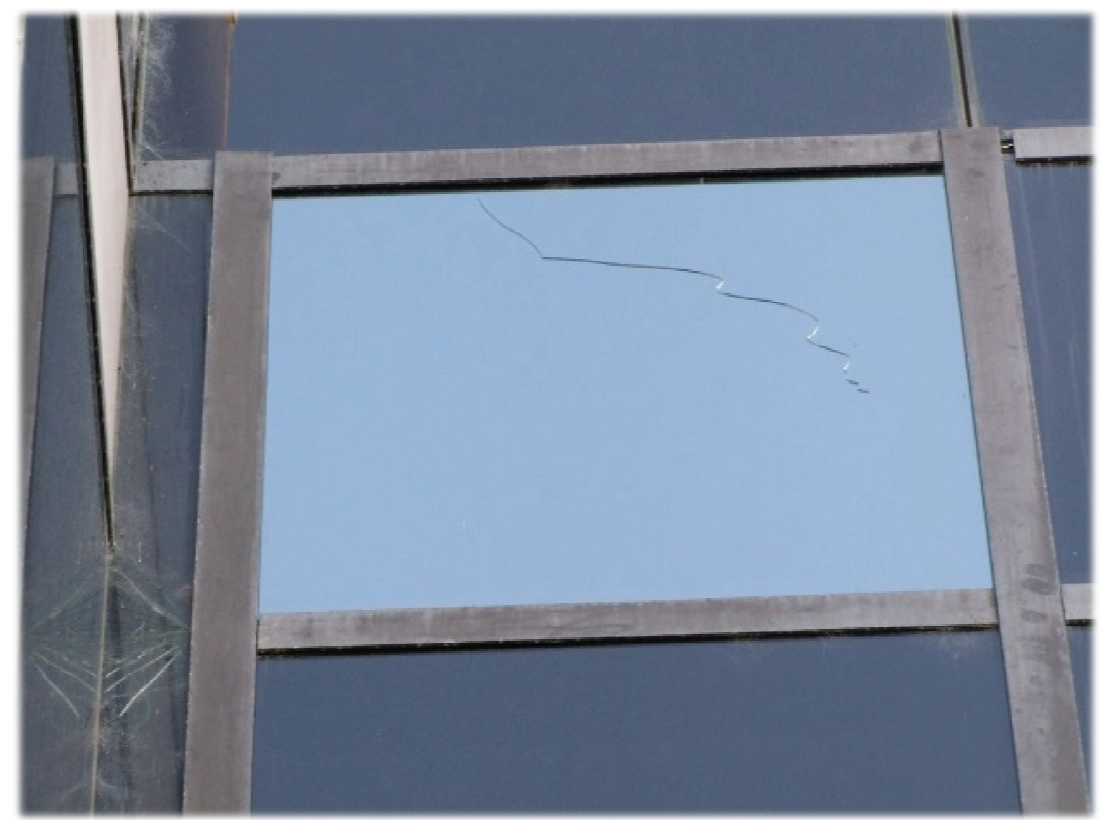

Fig. 3 Curtainwall, cracked glass: north face, May 9, 2011.

Two glass lights were broken in 2010 and they were replaced with new glass which did not precisely color-match the original. One of the replacements has again cracked (Fig 3), as has a panel adjacent to it. As so few glass panels in the curtainwall have broken, it is reasonable to conclude that this is not a systemic problem and glass breaking and falling due to earthquake effects in future is most unlikely.

Fig. 3 shows a glass panel which was previously broken and replaced in 2010 before the September 4, 
2010 earthquake. It and the panel to its left are the only panels found to have been broken after the February 22 earthquake.

The vertical joints in the mullions appear to have been set at $6 \mathrm{~mm}$, whereas good industry practice indicates that it should have been $10 \mathrm{~mm}$ or more. The seismic racking has resulted in joints of varying width. Mullion joints typically remained $6 \mathrm{~mm}$ at the mullion brackets but changed to $2 \mathrm{~mm}$ to $12 \mathrm{~mm}$ remote from the brackets. Also, the stack joint between panels (the horizontal movement joint) was set at only $6 \mathrm{~mm}$, whereas good industry practice indicates that it should have been approximately $24 \mathrm{~mm}$, to allow for manufacturing and installation tolerances, concrete edge beam creep, column shortening and thermal and seismic effects. This joint varied on site by approximately $\pm 2 \mathrm{~mm}$.

Despite the small joint sizes between the curtainwall panels, the curtainwall performed adequately in the seismic ultimate events in that there was no collapse.

It appears that the mullion joints (between the two

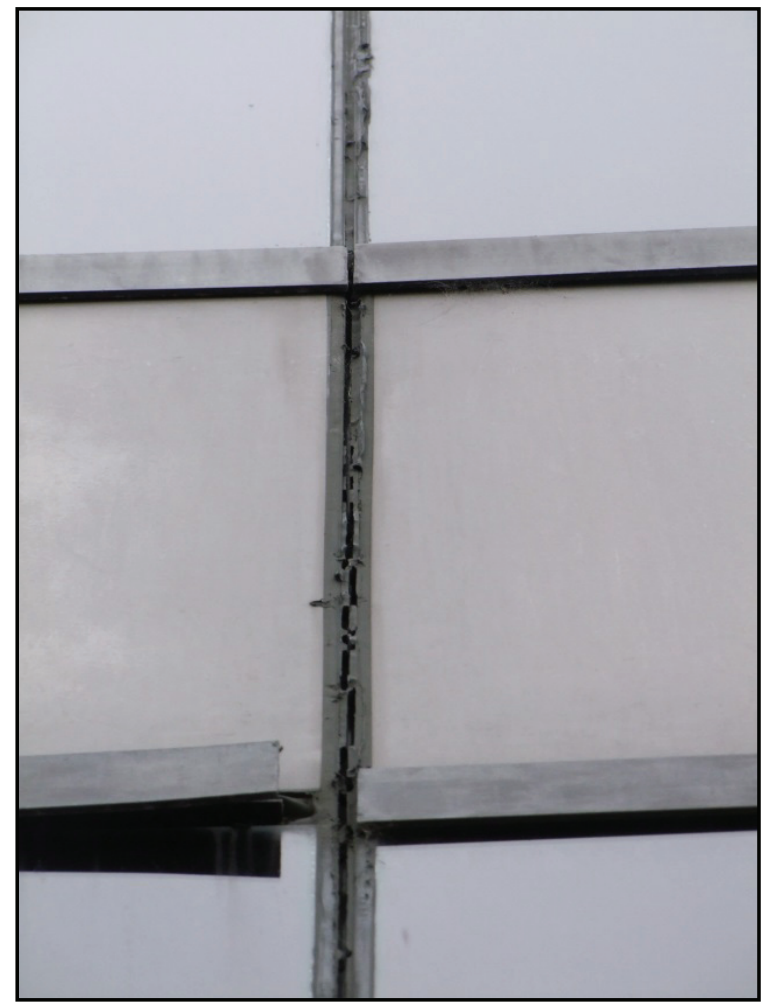

(a) sections which interlock at installation and make up the combined mullion) had been silicone sealed in a misguided effort to stop water ingress. Most of the silicone seals in the mullion joints have been ruptured by seismic movements as seen in Figs. $4 a$ and $4 b$. Some of the clip-on beads over the transoms were partly dislodged (Fig. 4a), although none had actually fallen off.

Both mullions have joints which were filled with silicone sealant, which has been ruptured by seismic movement.

The curtainwall mullion "dead load" brackets which are positioned just below the floor line (Fig. 5) resist both dead and wind loads. As installed, the dead load brackets have locked up the mullion joints, allowing no movement at the bracket positions. In an earthquake, the mullion joints open or close away from the dead load brackets and in so doing, bend the mullions causing stress in the mullions. Once the earthquake ceases and the load reduces to zero, the mullions stress relieve and tend to return to their original

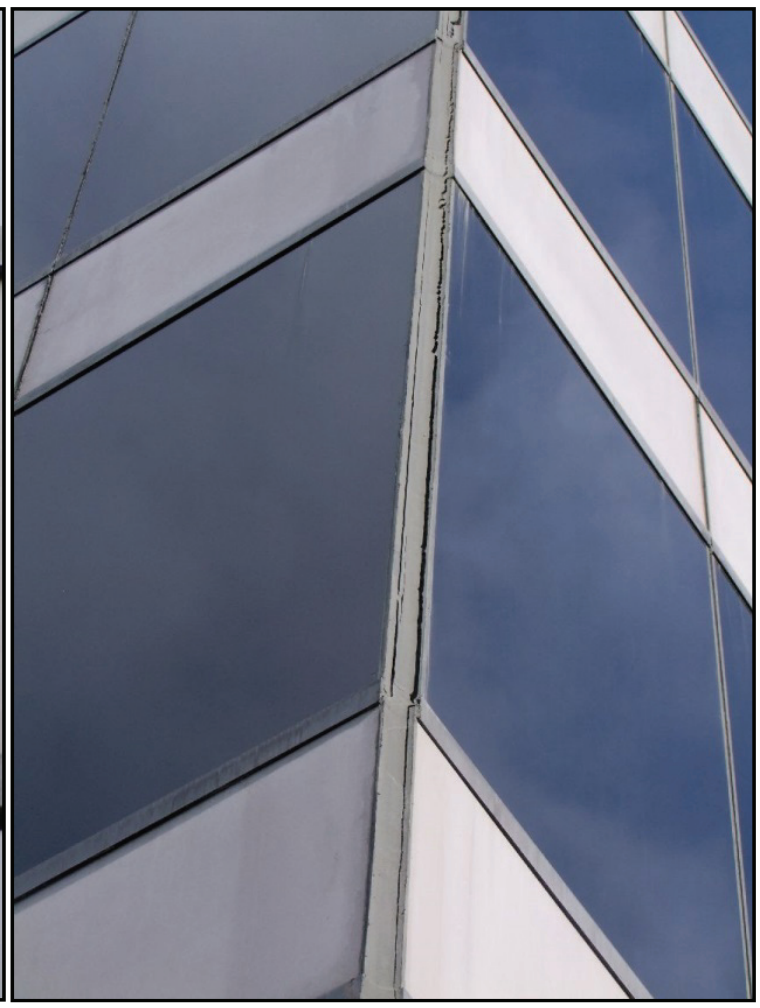

Fig. 4 Photos show: (a) a typical mullion; (b) a corner mullion.

(b) 


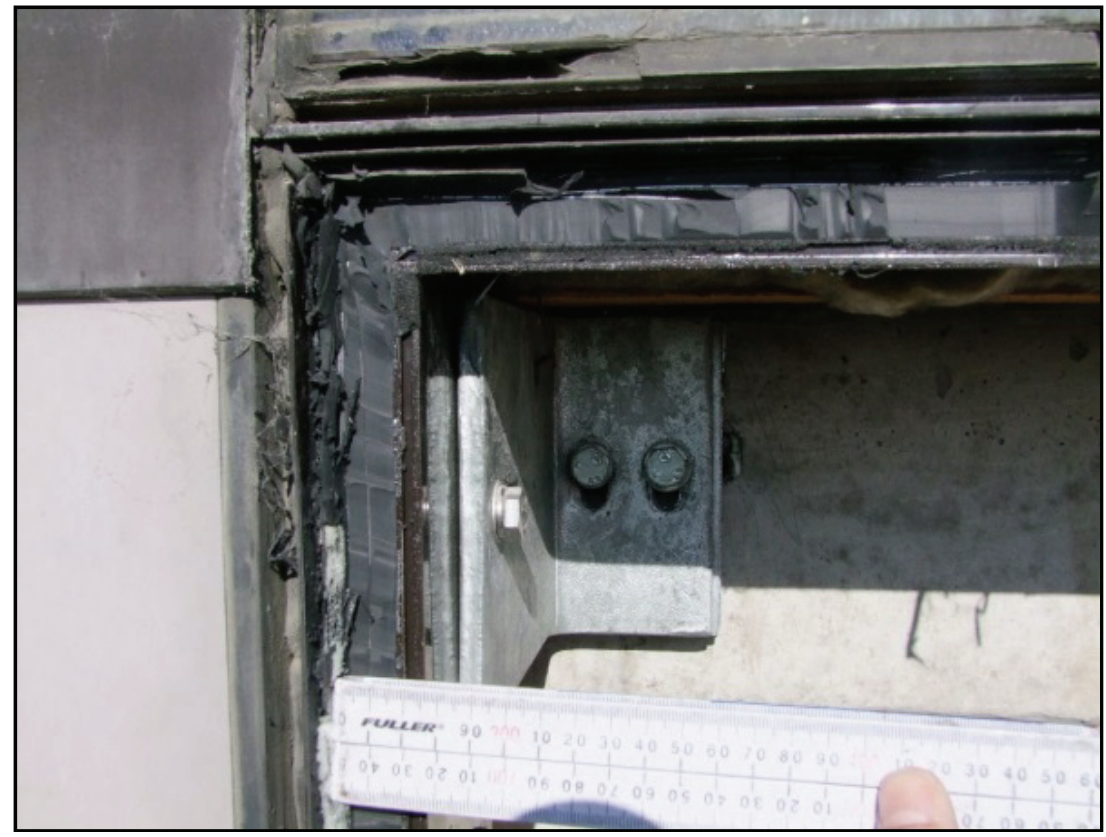

Fig. 5 Typical curtainwall dead load bracket.

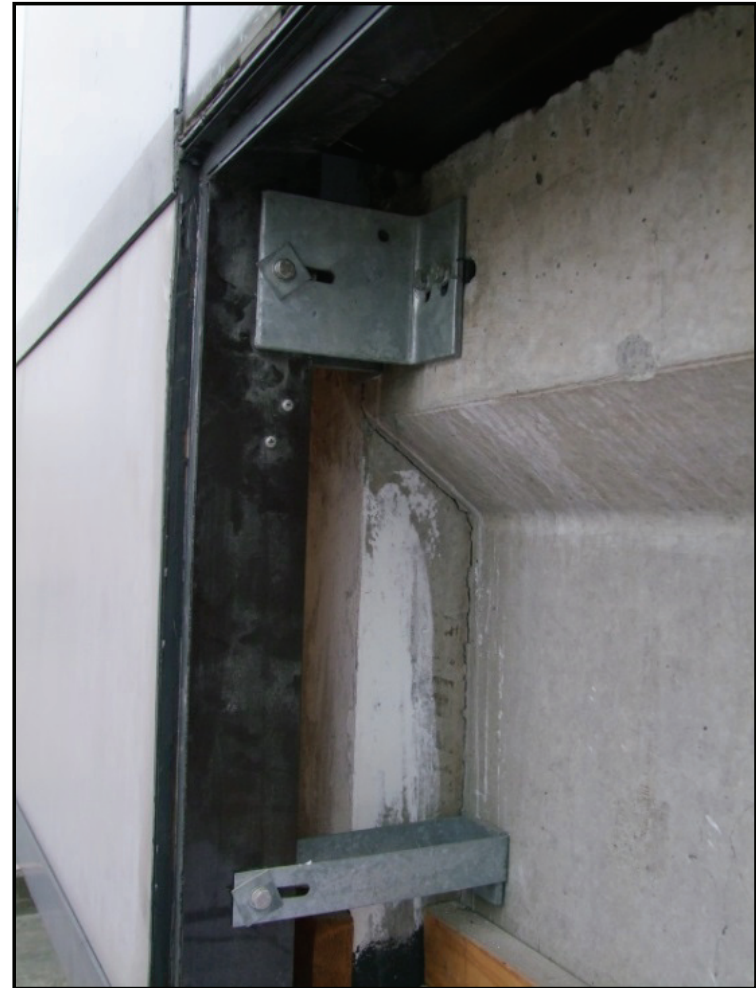

(a)

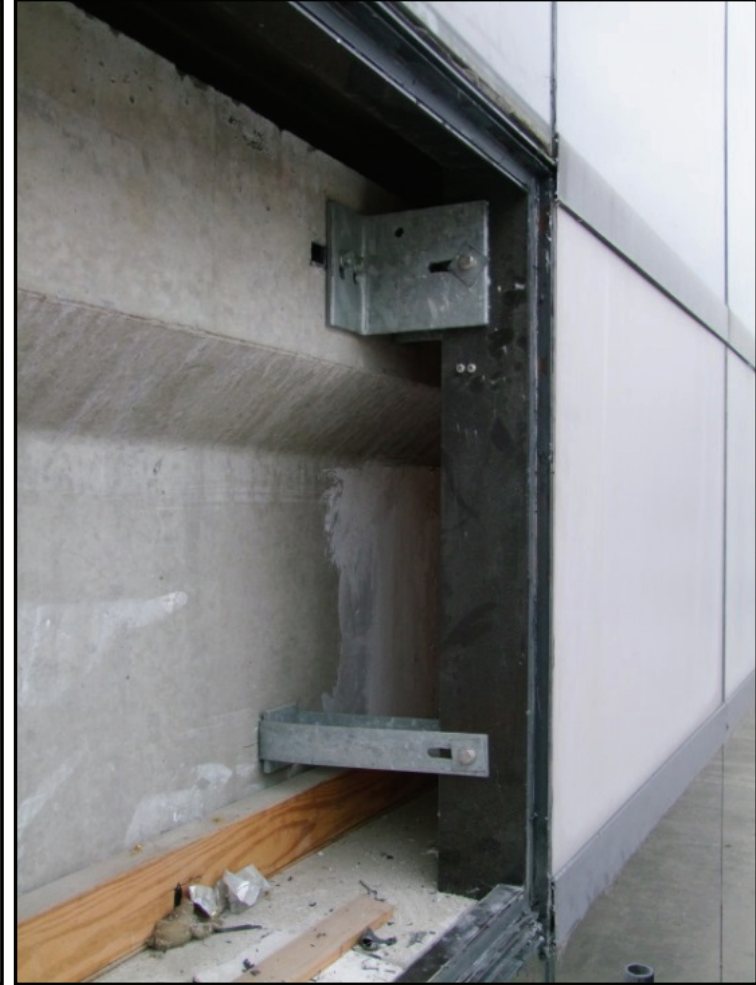

(b)

Fig. 6 The curtainwall brackets on either side of a corner mullion, with the spandrel removed.

(straight) positions and the joints to their as-installed size. This is what appears to have happened after the earthquakes in 2010 and the observed mullion joints would have been much larger or smaller during the earthquake.

The two types of brackets used to retain the curtainwall to the structure are in Fig. 6, with the spandrel panel removed. The top brackets are the "dead 
load" brackets, which resist both dead load and wind load. The lower brackets are the wind load brackets which resist wind load only. These brackets (Fig. 6) are at the corner of the inset at the middle of the faces, where effects of the seismic racking were less and the concrete has not been severely cracked. The wind load brackets are installed to the mullions at the building corners and the next two mullions, where the negative wind pressure is highest.

The result of the more severe February 22 earthquake was that the mullions close to the corner columns have been severely twisted and retain a permanent displacement and distortion. The mullion has also been substantially distorted at its joint with the gutter head transom. Local bucking of a mullion (which occurred only at the building corners (to the corner mullion and the two mullions either side of the corners)) due to the building structure movement at the corners is seen in Fig. 9b. This was observed at the site by failed sealant with permanent vertical and horizontal displacement of the two parts of the mullion in Fig. 7.

The severe trauma suffered by the structure at the building corners was observed around several brackets (as seen in Figs. 8a, 8b and 9a), once the spandrel panels had been removed. Cracking of the concrete in the spandrel was observed within approximately $3 \mathrm{~m}$ of the building corners. However, concrete cracking at column-to-edge beam junctions was observed in many

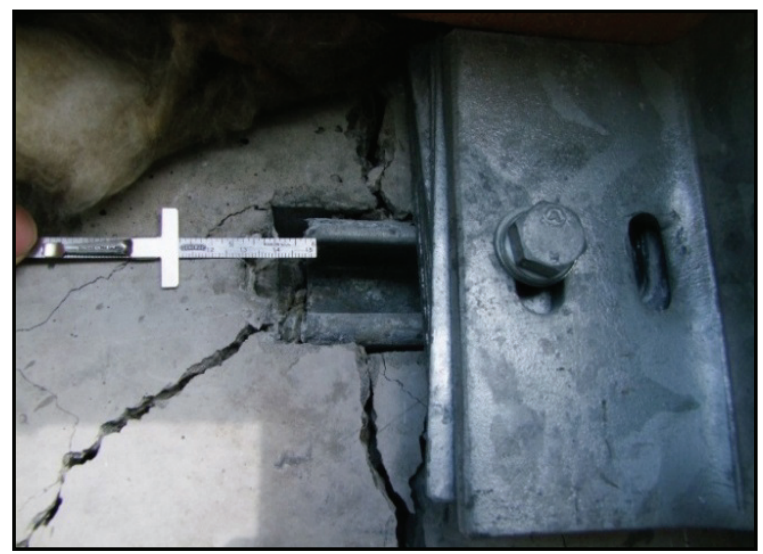

(a) places from inside the building as seen in Figs. 14a and $14 b$.

There was granite cladding installed on the south face around the building main entrance on both the podium and the tower, as shown in Fig. 10.

The red line in Fig. 10 delineates the structures of the podium and the tower. Only 8 panels of granite actually fell off and fell onto the awing over the entrance. These were from the podium at the tower corners (indicated with the yellow arrows in Fig. 10).

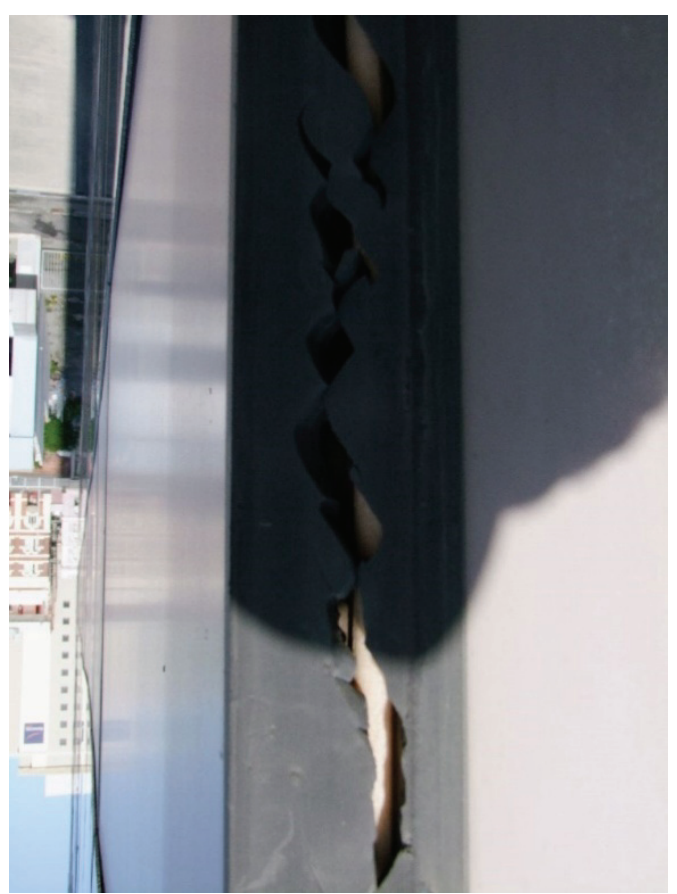

Fig. 7 Corner mullion; the seal in the mullion has ruptured and has remained open indicating permanent vertical and horizontal displacement of the two mullion sections.

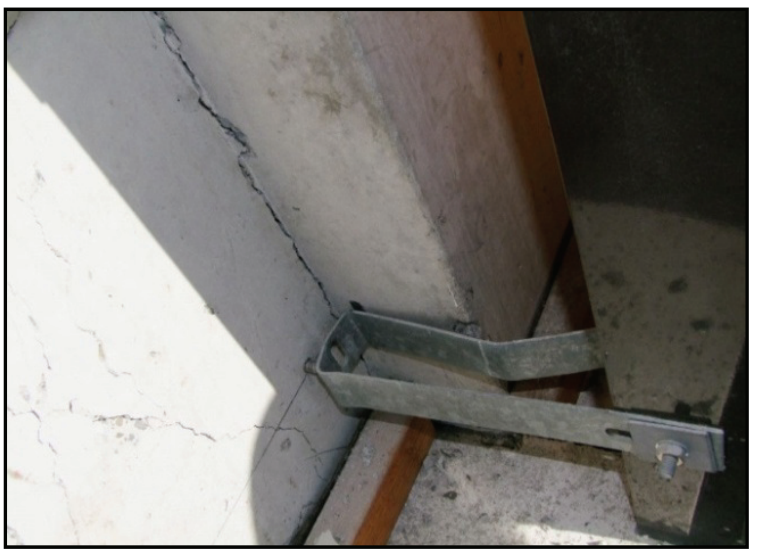

(b)

Fig. 8 Photos show: (a) a "dead load" bracket with the concrete of the column cracked around the "unistrut"; (b) a severely bent wind load bracket and a vertical crack between the concrete column and the concrete edge beam. 


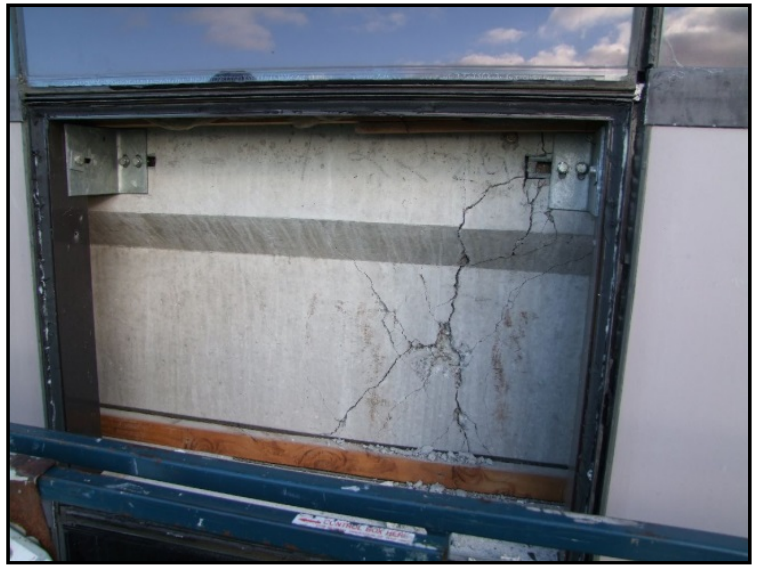

(a)

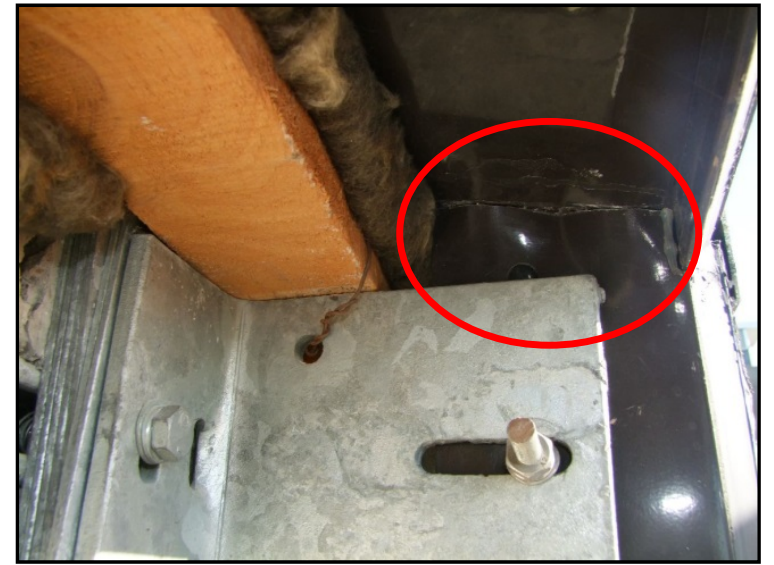

(b)

Fig. 9 Photos show: (a) cracking is an edge beam which is between the first and second mullions from the corner (the corner is at right, outside the photo); (b) a mullion with local bucking just above the dead load bracket, within the area of the red oval.

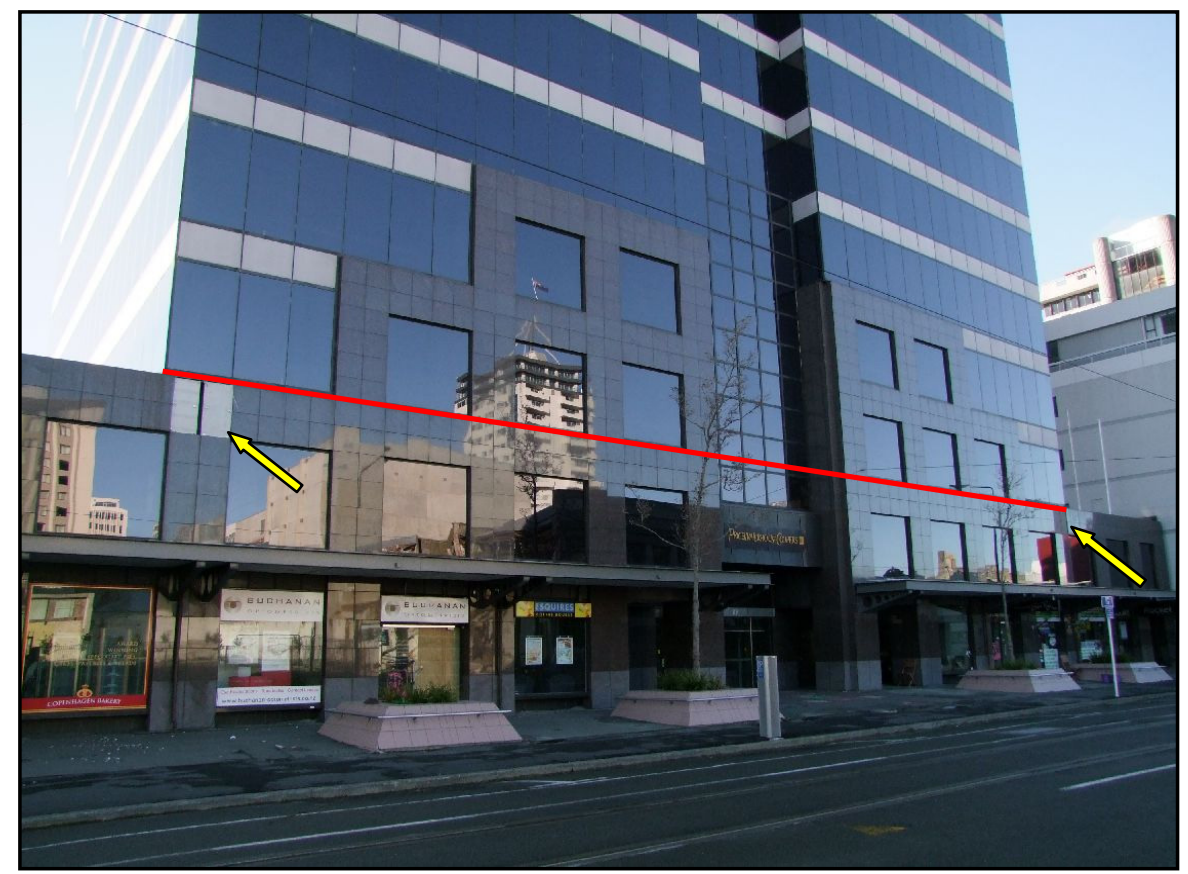

Fig. 10 Granite cladding on the south face.

This is likely to have been associated with movement between the podium and tower structures.

There has obviously been movement between the two structures as evidenced by the distorted membrane in Fig. 11.

The tile cladding on the other three (less visible) faces is a substitute for the granite cladding on the south face. The tiles are bonded with a cement-based adhesive to compressed fiber cement sheet which is supported on a timber frame. There were no obvious movement joints but obvious joints which had opened up due to seismic racking as seen in Fig. 12b (highlighted with the white arrows). Many of the tiles have de-bonded from their fiber cement sheet backing and are loose, as seen in Fig. 12a.

Fig. 13a shows an internal glass panel fixed between the end of an internal partition wall and a mullion. There is no movement allowance between the mullion and the failed glass. The glass is annealed (it is not safety glass) and it broke into large pieces with sharp edges. The internal glass partition in Fig. 13b was similarly and incorrectly also annealed glass; it should 


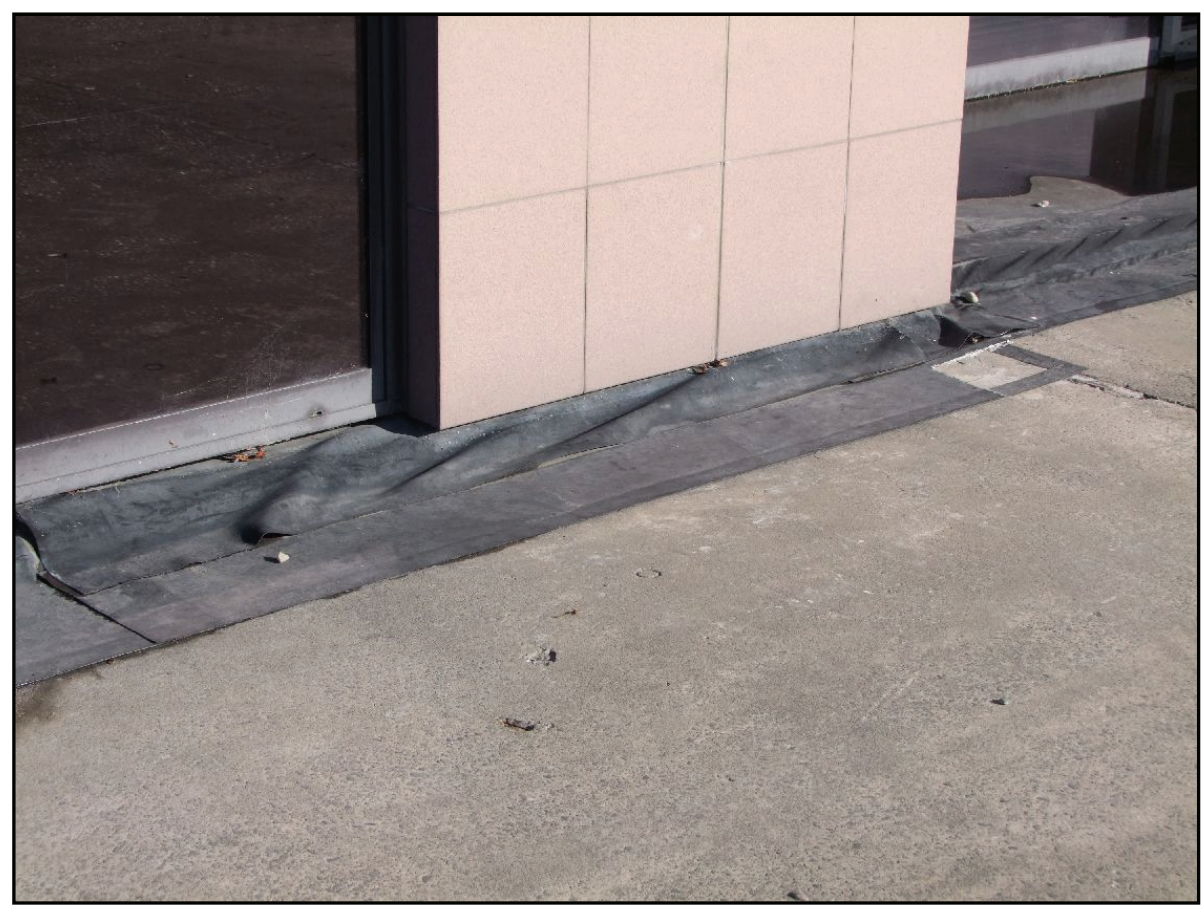

Fig. 11 The podium/tower structural interface.

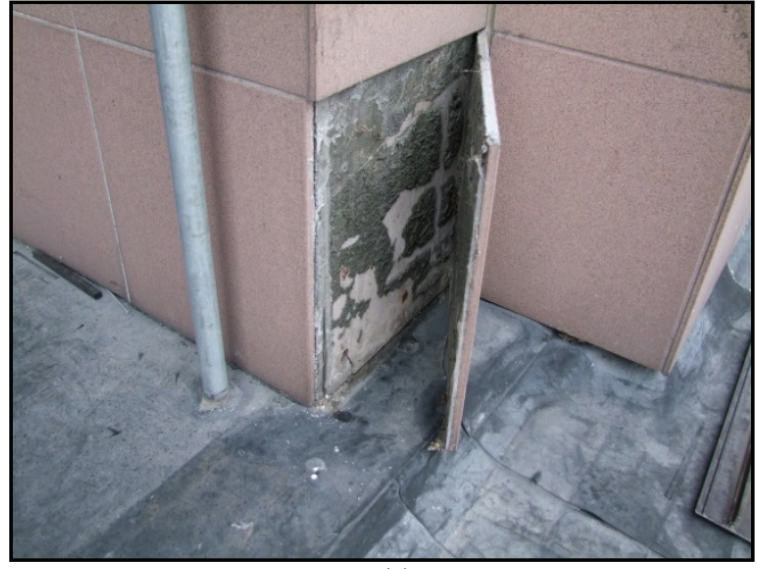

(a)

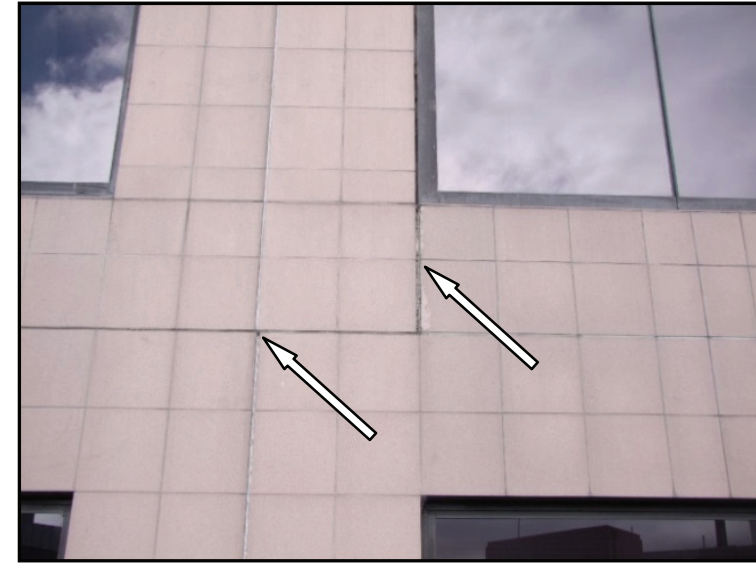

(b)

Fig. 12 Tile cladding: (a) shows a tile which has de-bonded; (b) indicates a building joint in the tile cladding on the Podium, highlighted with the white arrows.

have been toughened (tempered) or laminated safety glass. It also failed due to lack of movement joints around its perimeter. It was taped up post failure (as a safety measure) before the occupants were allowed back into the building for a short time to remove more important items from their offices. These glass failures clearly show that the correct safety glass should be used internally in an office building and that seismic movement allowances must be made for internal glass as it should be for external glass.

There was obvious cracking and spalling of the concrete at the column/beam junctions, which could be observed around the building perimeter and seen in Figs. 14a and 14b. This was obvious both below the joints edge-beam to column joints (Fig. 14a) where large pieces of concrete fell down to the floor impacting objects and possibly occupants below. There was also severe trauma of the structure at the floor joints 


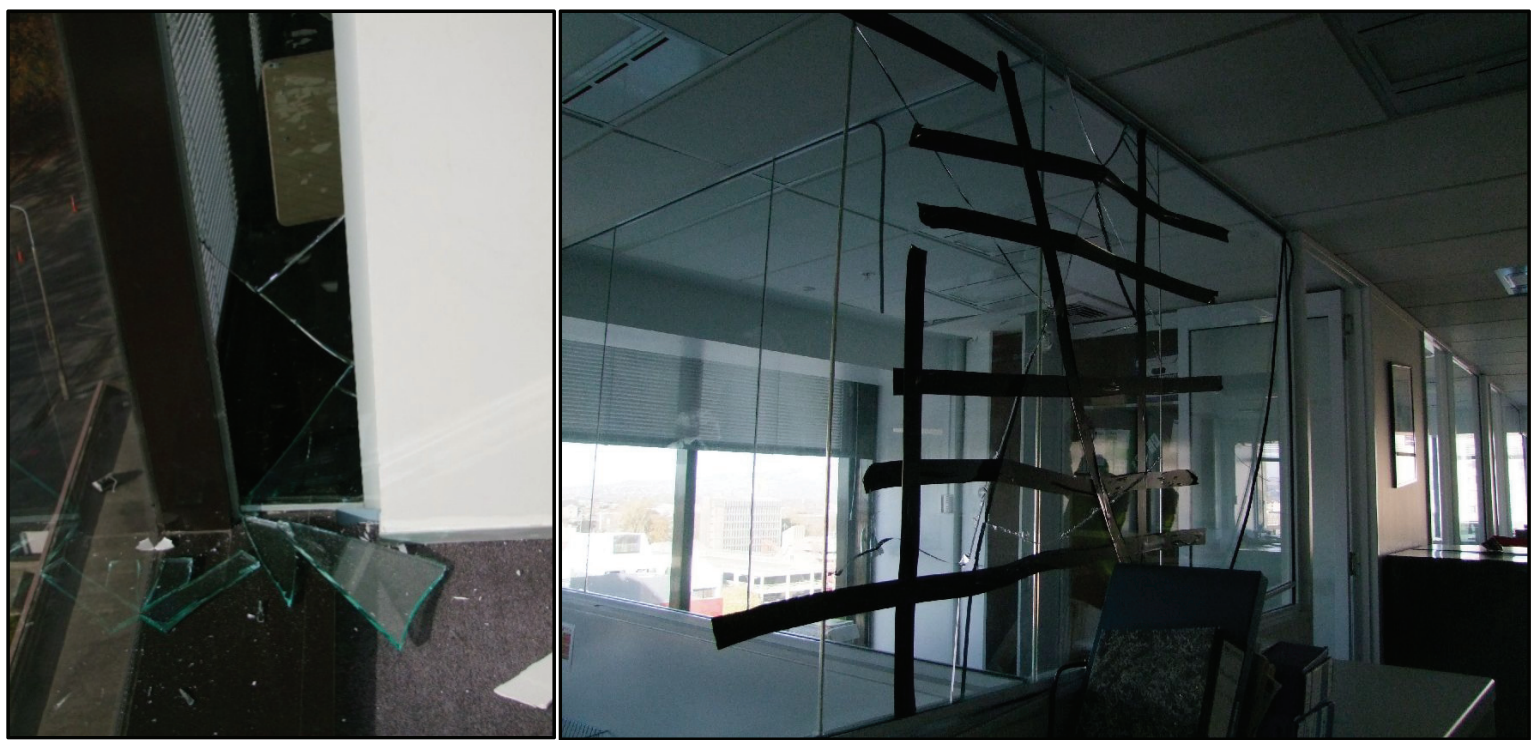

(a)

(b)

Fig. 13 Damaged: (a) failed glass of a partition at 90 degrees to the curtainwall; (b) failed glass of an internal glass office wall.

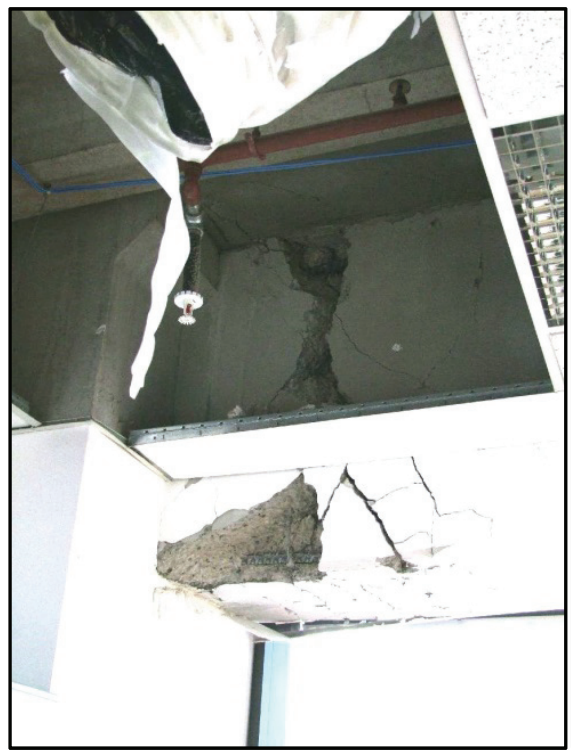

(a)

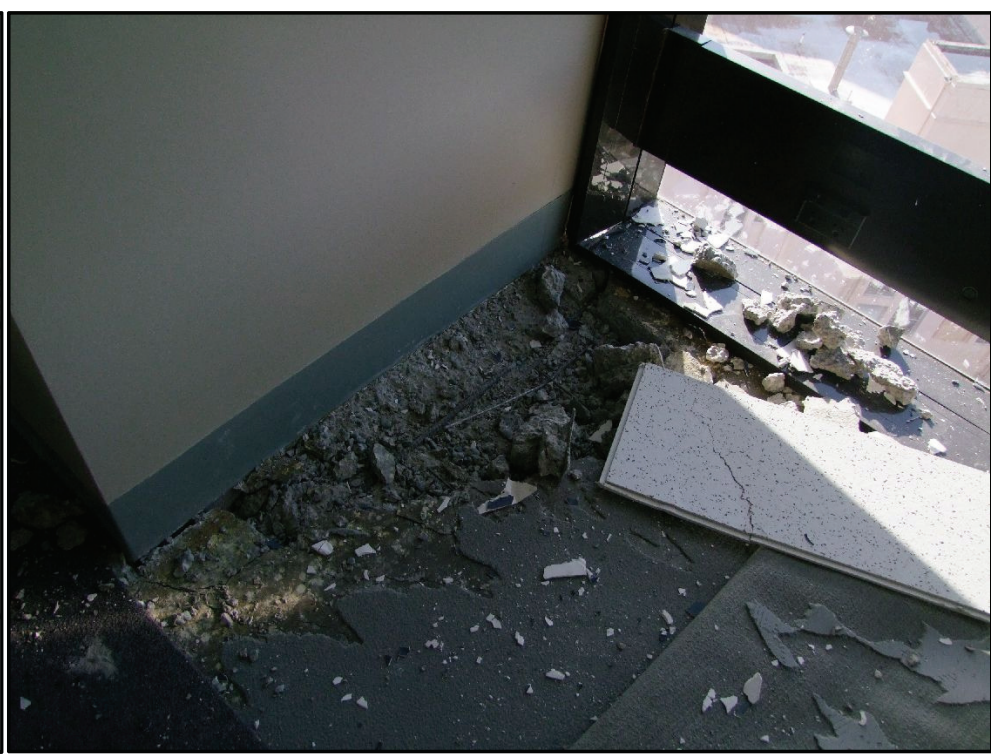

(b)

Fig. 14 Damaged internal concrete structure: (a) shows cracking is a concrete edge beam below a floor (above the ceiling); (b) shows internal structural damage at an edge-beam to column junction.

of the edge beam and columns as seen in Fig. 14b. This appeared to have erupted under the carpet with concrete spalled pieces.

\section{Conclusions}

The curtainwall survived the severe earthquakes of September 4, 2010 and February 22, 2011 without collapse as no components of the curtainwall actually fell from the building. The granite and tile facades also survived the both earthquakes substantially without collapse. Even though these façade elements had movement joints which were theoretically inadequate in accordance with accepted industry standards, they performed adequately.

Glass failures of internal office walls clearly show that the correct safety glass should be used internally in an office building and that seismic movement allowances must be made for internal glass as it should 
be for external glass.

Janus Facades' assessment is that a substantial part of the curtainwall was irreparably damaged, as there was permanent distortion in mullions and brackets (as seen in Figs. 4a, 4b, 7, 8b, 9a and 9b). This includes the corner panels at all building corners and four panels each side of the corners. Irreparable panels total approximately one half of all curtainwall panels. Janus Facades' recommendation was that the whole curtainwall be replaced because the undamaged part of the curtainwall would continue to perform poorly in rainstorms and because of the difficulties of designing an adequate interface between old and new curtainwall panels.

Janus Facades' also recommended complete replacement of the granite and the tiles and their support structures. The curtainwall performed adequately in the earthquake whereas the traditional timber frame, compressed cement fiber sheet and bonded tiles and granite failed. Janus Facades therefore recommended that the granite and tiles be redesigned as panels in curtainwall frames for adequate designed seismic resistance; in this case, the granite panels and tiles would be fitted into curtainwall panels in a factory and installed on site in the same manner as conventional curtainwall panels.

The new curtainwall should be designed, taking into account the expected seismic movements as determined by the building structural engineer. The curtainwall designer must determine the curtainwall panel movements which will occur when the advised building seismic movements apply and ensure that the curtainwall joints are adequately sized to allow that movement, including reasonable tolerances.

The assessment by structural engineers of the building structure was that it could be repaired. The owner's assessment was that demolition and rebuild was only marginally more expensive than repair and that a new building was preferable. As a consequence, the building has been demolished.

\section{References}

[1] Standards New Zealand. 1992. NZS 4203: 1992 New Zealand Standard: Code of Practice for General Structural Design and Design Loadings for Buildings; known as the Loadings Standard. Volume 1. Code of Practice Part 4 Earthquake Provisions.

[2] Standards Australia Limited/Standards New Zealand. 2002. AS/NZS 1170.4:2002 Structural Design Actions Part 4. Earthquake Actions.

[3] Singapore Standard CP 96:2002. Code of Practice for Curtain Walls.

[4] New Zealand Building Code, New Zealand Government Ministry of Business, Innovation and Employment. n.d. Clause B1 Structure.

[5] National Construction Code of Australia. 2012. Structural Provisions. Volume 1, Section B Structure; Part B1.

[6] AAMA. 2005. AAMA CW-DG-1-96 Editorial Revision: 5/2005 Curtain Wall Design Guide Manual.

[7] Government of Canada. 2004. Glass and Metal Curtain Walls; Best Practice Guide Building Technology. CMHC SCHL.

[8] GeoNet. 2011. M 6.3, Christchurch, 22 February 2011-Earthquake. Accessed January 6, 2017. http://info.geonet.org.nz/display/quake/M+6.3,+Christchu rch, $+22+$ February +2011 . 